\title{
Resiliência eleitoral dos presidentes latino-americanos após a crise de 2008 e o refluxo da onda rosa
}

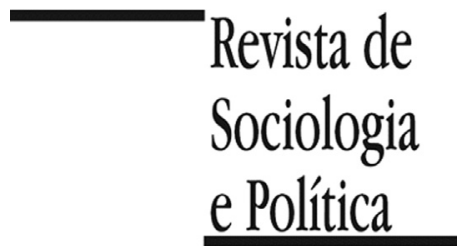

DOI 10.1590/1678-987320287303

\section{Diego Sanches Corrêa' \\ ICentro de Engenharia, Modelagem em Ciências Sociais Aplicadas, UFABC, São Bernardo do Campo, SP, Brasil.}

\begin{abstract}
RESUMO Introdução: Pretende-se explicar a capacidade de sobrevivência eleitoral dos presidentes latino-americanos em condições de instabilidade econômica e política. Materiais e Métodos: Foram testadas três hipóteses. Presidentes possuem maior capacidade de sobreviver eleitoralmente quando: 1) controlam o Legislativo; 2) controlam a sociedade civil e 3) são alinhados à esquerda radical. As variáveis utilizadas pelo trabalho são binárias e o método utilizado foi a Análise Comparada Qualitativa. Resultados: Por um lado, nenhuma das variáveis independentes é, isoladamente, condição necessária ou suficiente para a sobrevivência eleitoral dos presidentes latino-americanos. Por outro lado, elas demonstram que o controle do Legislativo e da sociedade civil garante a sobrevivência de presidentes alinhados a qualquer ideologia e que presidentes radicais de esquerda sobrevivem politicamente mesmo na ausência destes controles. Discussão: Os resultados ajudam a explicar um fato intrigante da conjuntura política latino-americana pós-crise global de 2008: a forte resiliência de alguns presidentes em situações altamente adversas. Enquanto alternâncias de poder ocorreram em diversos países governados pelo mesmo partido há mais de uma década, em outros mecanismos de accountability eleitoral parecem ter falhado para promover rotatividade de governo.
\end{abstract}

PALAVRAS-CHAVE: eleições presidenciais; América Latina; esquerda radical; sobrevivência eleitoral; QCA.

Recebido em 14 de Novembro de 2018. Aprovado em 14 de Setembro de 2019. Aceito em 26 de Outubro de 2019.

\section{Introduçãa ${ }^{1}$}

\footnotetext{
1 Agradeço aos comentários e sugestões dos três pareceristas anônimos da Revista de Sociologia e Política. Uma versão preliminar deste artigo foi apresentada no XI Encontro da $\mathrm{ABCP}$, realizado em Curitiba em 2018. Agradeço aos comentários e sugestões do debatedor Emerson Urizzi Cervi e demais participantes.
}

\footnotetext{
${ }^{2}$ Veja, por exemplo: Latin America: The 'pink tide' turns. 2015. BBC News, Londres, 11 dez. Disponível em

https://www.bbc.com/news/w orld-latin-america-35060390 (Acesso em 31 mai. 2020); The Death of the Latin American Left. 2016. The New York Times, 22. mar. Disponível em: https://www.nytimes.com/201 6/03/23/opinion/the-death-of-t
}

$\mathrm{E}$ m novembro de 2015, Mauricio Macri venceu a eleição presidencial argentina e encerrou doze anos de governo da Frente para la Victoria (FPV), uma facção esquerdista do Partido Justicialista (PJ). Foi a primeira vez que um político outsider, de fora das fileiras dos tradicionais $\mathrm{PJ}$ e Unión Cívica Radical (UCR), venceu uma eleição naquele país desde a fundação do PJ em 1946. No mês seguinte, os congressistas brasileiros iniciaram o processo de impeachment da presidente Dilma Rousseff, que culminaria com o fim de catorze anos de governo do Partido dos Trabalhadores (PT). Estes e outros eventos políticos recentes poderiam estar sinalizando o fim de uma era na América Latina, caracterizada pelo domínio político da esquerda e por políticas públicas orientadas para o combate à pobreza e à desigualdade social. Nos principais meios de comunicação internacionais, essas mudanças conjunturais foram interpretadas como sinais de esgotamento da agenda socialdemocrata e do início de um "giro à direita" no continente. ${ }^{2}$

De fato, a crise financeira mundial de 2008 e a consequente instabilidade econômica dos anos seguintes colocaram à prova a sustentabilidade da política econômica e social dos governos latino-americanos. Tanto a derrota eleitoral da FPV, quanto a queda do PT, podem ser em parte explicadas pela recessão. Por outro lado, a resiliência política de líderes de outros países, em condições pelo menos tão adversas quanto as observadas no Brasil e Argentina, chama a atenção por contradizer a lógica do accountability eleitoral. Afinal de contas, é esperado que os eleitores punam o governo nas urnas e que coalizões governistas no Legislativo se desintegrem em situações de crise econômica. Como explicar então a vitória do situacionista Lenín Moreno no Equador em 2017, 
he-latin-american-left.html. (Acesso em 31 mai. 2020). após um ano de queda do PIB, ou a capacidade de Nicolás Maduro de se manter no poder e vencer eleições num cenário econômico catastrófico que já ganha contornos de crise humanitária, ou ainda a resiliência de Daniel Ortega diante de protestos que se estendem desde 2013 e que já deixaram centenas de mortos na Nicarágua?

Para entender esta diferença na capacidade de sobrevivência política de líderes e partidos de esquerda, devemos começar reconhecendo que, embora todos tenham sido copartícipes da "onda rosa" dos anos 2000, eles possuem agendas e estilos de governo bastante distintos (Castañeda, 2006; FloresMacías, 2010; Levitsky \& Roberts, 2011 Madrid 2010; Weyland, 2009). A esquerda que governou a Argentina, o Brasil, o Chile e o Uruguai, foram menos intervencionistas, tenderam a costurar alianças mais amplas com distintos segmentos da sociedade civil e implementaram políticas sociais de caráter mais impessoal e focalizado. Já na Bolívia, Equador e Venezuela, países mais dependentes economicamente da extração de recursos naturais, a esquerda foi mais intervencionista, nacionalista e generosa na distribuição de benefícios sociais. Seguindo a nomenclatura proposta por Weyland (2009), chamarei a esquerda que governou aquele primeiro grupo de países de "moderada" e a que governa este segundo grupo de "radical", mas a literatura é repleta de outras nomenclaturas para distingui-las. É possível então, com base no reconhecimento desta distinção, reelaborar a pergunta proposta acima para: Como explicar a maior resiliência política da esquerda radical, comparativamente à esquerda moderada, diante de situações econômicas adversas?

Esta pergunta ainda não seria a mais adequada, entretanto. Ela poderia nos induzir a interpretar de forma demasiado simplista uma conjuntura política em que forças políticas alinhadas a outras orientações ideológicas também são componentes importantes. Na República Dominicana, por exemplo, é um partido de centro-direita que mantém o controle do governo desde 2004 e os mecanismos que explicam a sua resiliência são similares aos utilizados pela esquerda radical nos países andinos. Em outros casos, foi a esquerda moderada quem se beneficiou das dificuldades geradas pela crise dos anos 2010. No México, por exemplo, o conservador Partido Acción Nacional (PAN) foi derrotado pelo também conservador Partido Revolucionario Institucional (PRI) em 2012 e no recente pleito de 2018 a esquerda conquistou o poder pela primeira vez na história do país, com o triunfo de Andrés Manuel López Obrador. Fenômeno semelhante ocorreu na Costa Rica, com a vitória do Partido Acción Ciudadana (PAC) em 2014, de tendência socialdemocrata, e sua reeleição recente em 2018. Nestes países ocorreu, portanto, um "giro à esquerda" tardio. Assim, se pretendemos entender os mecanismos que explicam a sobrevivência de líderes e partidos políticos em condições claramente adversas, precisamos orientar nossas investigações por uma questão de pesquisa mais geral. É verdade que a longevidade da esquerda radical na Bolívia, Equador e Venezuela salta aos olhos, o que torna este radicalismo um forte candidato a variável explicativa. Porém, as circunstâncias que favorecem esta sobrevivência política não se confundem necessariamente com fatores de cunho ideológico. Há outros mecanismos em jogo que independem de ideologia.

Demonstrar a importância destes mecanismos é o objetivo central deste trabalho. Com base em análises de eleições realizadas em dezoito democracias presidencialistas latino-americanas entre 2009 e 2017, pretendo explicar porque alguns presidentes foram bem-sucedidos eleitoralmente e se mantiveram no poder, enquanto outros não. Para isto, além do perfil ideológico do chefe de governo, analiso a importância de outros dois fatores teoricamente capazes de melhorar seus prognósticos de sobrevivência: o controle sobre o Legislativo e o controle sobre a sociedade civil. Na próxima seção, apresento uma discussão teórica que justifica o foco da pesquisa nestes dois fatores. Em seguida, 
descrevo e justifico minha abordagem metodológica, a análise comparada qualitativa (ACQ), e apresento os dados que utilizo. Na seção subsequente, discuto os resultados da análise, os quais corroboram a importância das variáveis explicativas. Finalmente, discuto as implicações destes resultados e a sua utilidade para compreender eventos políticos recentes na América Latina.

\section{Teoria: Ideologia, controle e sobrevivência política}

${ }^{3}$ De acordo com dados compilados pelo World Economic Outlook Database do Fundo Monetário Internacional (FMI), o crescimento econômico médio anual da América Latina e Caribe foi de cerca de $1,5 \%$ na década de $1980,3,3 \%$ na de $1990,3,3 \%$ na de 2000 (mesmo com a forte retração de 2009) e $1,8 \%$ na de 2010 (até 2017).
A década de 2010 foi muito difícil economicamente para os países latino-americanos, devido aos efeitos da crise financeira global de 2008. Após uma retração de quase dois pontos percentuais do PIB em 2009, o crescimento médio anual da América Latina e Caribe na década seguinte está sendo o pior desde os difíceis anos 1980. ${ }^{3}$ Este é um dado importante, porque sugere que as dificuldades dos presidentes latino-americanos para se manter no poder ou eleger seus sucessores foram provavelmente as maiores desde a onda de transições democráticas de décadas atrás. Diversos estudos sobre eleições latino-americanas demonstram que o estado da economia tem uma forte influência, possivelmente a mais forte, no desempenho eleitoral de candidatos à reeleição (Remmer, 1991; Samuels, 2004; Corrêa, 2015). Como consequência, se a alta demanda global por commodities favoreceu as exportações, o crescimento econômico e a sobrevivência eleitoral de diversos líderes e partidos latino-americanos nos anos 2000, importantes revezes políticos foram observados na década seguinte. A socialista Michelle Bachelet foi sucedida por um líder conservador em 2010, depois de vinte anos de domínio político da Concertación. O primeiro líder de esquerda paraguaio sofreu um impeachment fulminante em junho de 2012, e o poder voltou para as mãos dos colorados na eleição do ano seguinte. Macri derrotou os Kirchner em 2015 e o Congresso brasileiro derrubou Dilma Rousseff em 2016. Por outro lado, forças políticas que conquistaram o poder em algum momento dos anos 1990 ou 2000 continuavam governando a Bolívia, El Salvador, Equador, Honduras, Nicarágua, República Dominicana, Uruguai e Venezuela em fins de 2018. Destes, apenas o PLD dominicano e o Partido Nacional de Honduras (PNH) não são classificados como de esquerda pela literatura. É difícil explicar a sobrevida destes partidos com base apenas num suposto sucesso de suas administrações. Quase todos enfrentaram violentos protestos nas ruas e graves dificuldades econômicas em pelo menos algum momento de seus mandatos, inclusive às vésperas de eleições. Como explicar então a maior capacidade de certos chefes de governo para se perpetuar no poder, mesmo diante de condições tão adversas?

Uma possibilidade é o controle exercido por estes governantes sobre o Legislativo. Em países presidencialistas, onde os poderes são independentes, uma relação conflituosa entre o Executivo e o Legislativo pode se tornar uma forte ameaça à governabilidade e ao sucesso da administração presidencial (Linz, 1991). Via de regra, é ao Legislativo que incumbe o papel de fiscalizar o Executivo, contrapor suas iniciativas e até de depor o presidente, como ocorreu recentemente no Brasil (2016), Guatemala (2015), Honduras (2009) e Paraguai (2012). Esta capacidade que o Legislativo tem de restringir as ações do Executivo é costumeiramente interpretada como benéfica em regimes democráticos, pois enfraquece tendências autoritárias e promove agendas moderadas e politicamente viáveis (O’Donnell, 1994). Há pelo menos duas maneiras através das quais o presidente pode anular este mecanismo de freios e contrapesos, abrindo caminho para a utilização de recursos do Estado em prol de sua sobrevivência política. A primeira delas é política e conjuntural: o controle da maioria das cadeiras da legislatura pelo partido do presidente. É uma maneira direta, mas extremamente difícil, dado que todos os países latino-americanos adotam sistemas eleitorais de representação proporcional para pelo menos parte das cadeiras (Anastasia, Melo \& Santos, 2004) e a maioria convive com partidos fracamente 
institucionalizados (Mainwaring, 2018). Há, portanto, uma propensão institucional à volatilidade eleitoral e à fragmentação partidária, a qual dificulta a conquista da maioria das cadeiras por apenas um partido. Apesar desta improbabilidade, o controle unipartidário do Legislativo pelo Executivo não tem sido um fenômeno raro no continente.

A segunda forma de controle é institucional: fracas prerrogativas do Legislativo para fiscalizar e vetar medidas do Executivo, bem como a baixa frequência com que as exerce na prática quando as tem. Este mecanismo pode estar correlacionado com a força do partido do presidente no Legislativo, na medida em que maiorias unipartidárias são mais propensas a delegar autoridade ao chefe de governo, mas nem sempre isto ocorre e é mais correto tratá-lo como uma variável a parte. O Legislativo que se abstém de exercer seu poder fiscalizatório e contestatório, seja porque a Constituição restringe esta capacidade, seja de forma voluntária, abre caminho para o presidente implementar a sua agenda e utilizar os recursos do Estado de forma irrestrita. Pode configurar-se, então, um contexto de democracia delegativa (O'Donnell, 1994). De fato, um tal cenário acarreta enormes riscos para o país e, consequentemente, para a sobrevivência política do presidente, ainda que as relações entre os poderes deixem de ser um obstáculo à governabilidade. Quando medidas radicais ou arbitrárias não são confrontadas pelos legisladores, as reações tendem a acontecer nas ruas e a se tornar violentas. De qualquer forma, na medida em que o Executivo é capaz de alocar os recursos do Estado com liberdade, ele pode direcioná-los para os aparatos de repressão, combatendo os riscos políticos gerados por suas próprias ações.

Outra explicação para a longevidade de chefes de governo é o controle sobre a sociedade civil, também uma fonte potencial e perigosa de instabilidade política. Bases sólidas e leais de apoio na sociedade permitem ao presidente contar com uma proporção estável de votos nas eleições que disputa. Igualmente importante, elas se tornam um ativo político valioso quando protestos de oposicionistas irrompem, pois podem ser confrontados e neutralizados com contraprotestos de apoiadores. Para obter este controle, o presidente pode, primeiramente, convencer os cidadãos de que a manutenção dos benefícios sociais distribuídos pelo governo depende da continuidade do atual líder ou partido no poder. Se o eleitor acredita que programas de transferência de renda, o acesso à saúde, à educação e à moradia ou o crédito para consumo e investimento irão acabar com a mudança de governo, ele hesita em apoiar alternativas. Um método eficaz para fomentar esta percepção no eleitorado é influenciando politicamente os trabalhos dos servidores públicos e impedindo que se orientem por princípios clássicos da burocracia weberiana, como impessoalidade, rigidez procedimental e meritocracia. Quando símbolos partidários estampam campanhas de cadastramento, eventos de distribuição de benefícios e inaugurações de órgãos públicos, os beneficiários passam a ter dificuldades para distinguir entre servidores públicos e agentes partidários. É um cenário em que o partido e a administração pública se confundem na prestação de serviços sociais. Handlin (2013 denominou políticas sociais implementadas desta forma de "mobilizadoras", pois "incentivam a organização social entre beneficiários e permitem vínculos entre estas organizações e partidos de esquerda, facilitando a reivindicação de crédito e o recrutamento pela esquerda" (Handlin, 2013 p. 1582 , tradução minha). ${ }^{4}$

4 Trecho original, em inglês: "Mobilizational policies incentivized social organization among beneficiaries and allowed for linkages between these organizations and left parties, facilitating credit claiming and recruitment by the left."
O segundo instrumento utilizado por presidentes para controlar e fortalecer bases de lealdade na sociedade civil pode parecer contra intuitivo à primeira vista: mecanismos de participação direta da população na produção de políticas públicas, especialmente em âmbito local. Quando criados ou regulados de cima para baixo e baseados primariamente na participação do cidadão comum não organizado, instituições participativas criam um elo político direto entre a 
população e o governo. Por não cumprirem o papel de canalizar demandas plurais da sociedade civil organizada, estes fóruns e conselhos comunitários acabam mais facilmente sendo liderados por agentes partidários para fins de doutrinação política. Os recursos controlados pelos conselhos tendem a ser substanciais e direcionados para beneficiar cidadãos leais, o que estimula ainda mais a participação e a lealdade. Diferentemente do observado em países onde as instituições participativas canalizam demandas autônomas e plurais da sociedade civil, a taxa de participação em comitês locais controlados e cooptados pelo governo tende a ser altíssima, uma vez que os debates são menos técnicos, mais transversais entre as áreas de políticas públicas e mais acessíveis ao cidadão comum. Ao contrastar as instituições participativas venezuelanas com as brasileiras, por exemplo, Silva (2016) notou que, enquanto na Venezuela "trata-se de participação focada na atuação da cidadania comum ou anteriormente 'desorganizada', apesar da participação de militantes de organizações sociais, de integrantes do Partido Socialista Unida da Venezuela (PSUV), etc." (Silva, 2016, p. 660), no Brasil os conselhos "enfatizam a cidadania organizada, pois somente se prevê a participação de representantes de organizações sociais [...] ou de especialistas, [...] são majoritariamente capacitados a expressar posicionamentos, mas sem caráter vinculante [...] e são constituídos por representantes seja da sociedade civil, seja da administração federal. (Silva, 2016, p. 665). As relações entre Estado e movimentos sociais no Equador se assemelham ao padrão encontrado na Venezuela, segundo o mesmo autor (Silva, 2015).

Em resumo, governos que conseguem controlar o poder Legislativo e a sociedade civil através dos mecanismos descritos acima estão em melhores condições de se perpetuar no poder, vencendo eleições e sufocando protestos, mesmo diante de condições econômicas desfavoráveis. A maioria unipartidária em um Legislativo que não fiscaliza o Executivo permite ao governo implementar sua agenda com menos dificuldades e, mais importante, utilizar recursos do Estado para fortalecer suas bases de lealdade na sociedade civil e reprimir protestos de opositores. Igualmente, a politização dos serviços e benefícios sociais e o estímulo à participação direta do cidadão comum em fóruns deliberativos locais permite ao governo direcionar os recursos do Estado para o benefício de cidadãos fiéis, fortalecendo suas bases e enfraquecendo potenciais focos de oposição. Portanto, duas hipóteses que orientam as análises das seções seguintes são:

$$
\begin{aligned}
& \mathrm{H}_{1}=O \text { controle sobre o Legislativo promove a sobrevivência política do } \\
& \text { governo. }
\end{aligned}
$$

$\mathrm{H}_{2}=O$ controle sobre a sociedade civil promove a sobrevivência política do governo.

Embora a esquerda radical tenha, na maioria das vezes, sido bem-sucedida em obter estas duas formas de controle, frequentemente através da adoção de novas Constituições, não há uma relação necessária entre ideologia e estas variáveis. Devemos, portanto, tratar a inclinação ideológica do partido no poder como um fator distinto e verificar se influencia de maneira autônoma a capacidade de sobrevivência dos presidentes latino-americanos. A principal razão para acreditarmos que isto ocorre é o fato de a agenda radical de esquerda elevar a redistribuição de renda a prioridade máxima de Estado. Este objetivo é perseguido via políticas sociais agressivas, generosos programas de transferência de renda que beneficiam uma proporção muito alta da população e, frequentemente, nacionalizações de indústrias extrativas. Nos países latino-americanos, onde a maior parte da população é pobre e se beneficia da redistribuição de renda, espera-se que o eleitorado reconduza partidos esquerdistas ao cargo em muitas eleições sucessivas. Trata-se apenas do accountability eleitoral 
funcionando em um regime democrático. Assim, as análises que se seguem também buscarão verificar uma terceira hipótese:

$\mathrm{H}_{3}$ : A agenda da esquerda radical promove a sobrevivência política do governo.

Considerar a ideologia do governo uma variável que afeta, por si só, a capacidade de sobrevivência do presidente ao longo do tempo é uma vantagem analítica deste trabalho. Afinal de contas, há casos de líderes radicais de esquerda que não foram capazes de controlar o Legislativo e a sociedade civil, bem como de líderes alinhados a outras ideologias que o foram. Mesmo que essas variáveis se confundissem, o método de análise descrito abaixo identificaria esta associação e nos levaria a considerá-las expressões de um mesmo fenômeno. Não é o que ocorre, como será demonstrado. A seguir, detalho minha abordagem metodológica e descrevo a forma como operacionalizei as variáveis dependentes e independentes.

\section{Método e Dados}

${ }^{5}$ Compõem a amostra de países deste trabalho: Argentina, Bolívia, Brasil, Chile, Colômbia, Costa Rica, El Salvador, Equador, Guatemala, Honduras, México, Nicarágua, Panamá, Paraguai, Peru, República

Dominicana, Uruguai e

Venezuela.

${ }^{6} \mathrm{Na}$ Venezuela, uma eleição extraordinária foi realizada em 2013 em virtude da morte do presidente anterior.
Este trabalho analisa dados do evento em que o risco de queda do chefe de governo é maior em um regime democrático presidencialista: a eleição presidencial. Para explicar diferenças nas capacidades de sobrevivência dos líderes políticos latino-americanos, foram analisadas todas as trinta e sete eleições presidenciais que ocorreram nas dezoito democracias presidencialistas do continente entre 2009 e 2017. ${ }^{5}$ Com exceção da Venezuela em 2013, todas estas eleições foram realizadas no momento previsto pelo calendário eleitoral, com frequência variando de quatro a seis anos. ${ }^{6} \mathrm{O}$ número de observações para cada caso foi de uma para o México e Paraguai, três para o Chile, Equador e Honduras e duas para os outros treze países. Note que, embora o curto período de análise restrinja a quantidade de observações do banco de dados, temos a vantagem de desconsiderar os anos de forte crescimento provocado pelo "boom das commodities" e focar num momento de economia mais instável. Como mostra a Figura 1, a taxa média de crescimento da América Latina foi negativa em três dos nove anos analisados (2009, 2015 e 2016), algo que não acontecia desde 1990. A maioria dos países da amostra experimentou pelo menos um ano de recessão ou de forte redução da taxa de crescimento logo após a crise global

Figura 1 - Taxa de crescimento econômico da América Latina a preços constantes

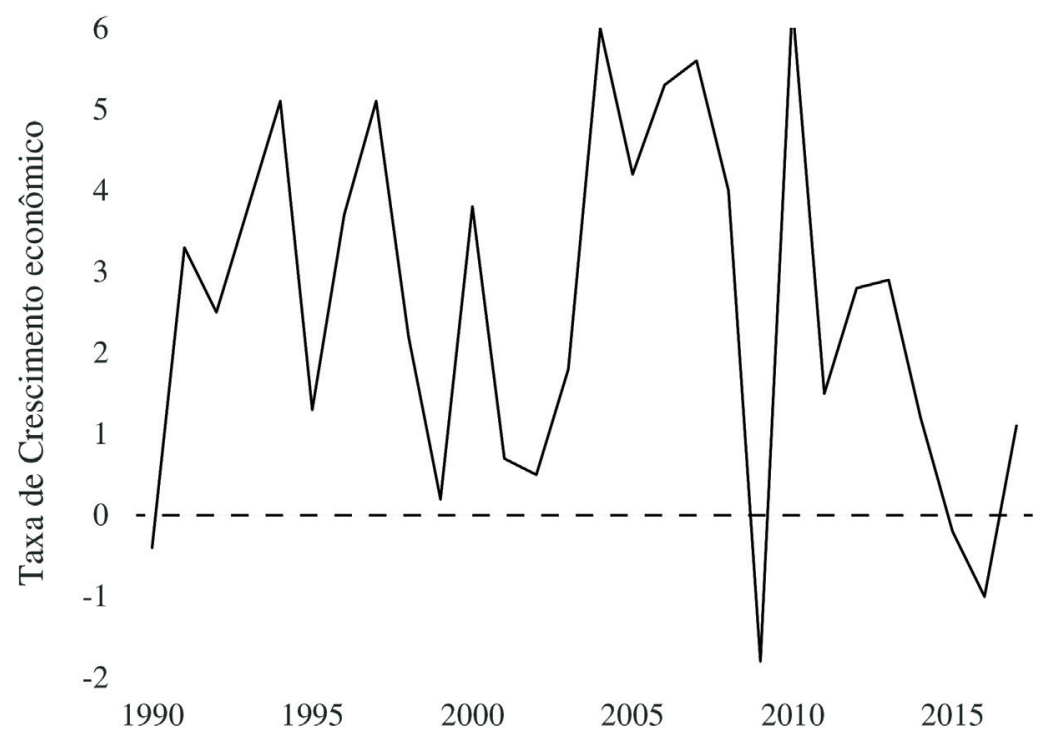

Fonte: Elaboração própria a partir de CEPALSTAT. 
${ }^{7}$ Num banco de dados com poucos casos, cada variável independente adicional diminui os graus de liberdade e a capacidade de inferência do modelo analítico. Assim, o foco da análise recaiu apenas sobre as três variáveis enunciadas nas hipóteses $\mathrm{H} 1$, $\mathrm{H} 2$ e H3. A restrição temporal ajuda a diminuir não só a influência do estado da economia, mas também de outros fatores potencialmente importantes para explicar a sobrevivência eleitoral dos presidentes.
${ }^{8}$ No caso da Colômbia, que realiza eleições legislativas de 2008. A única exceção é a Bolívia, que manteve altas taxas de crescimento em todo o período. Assim, a restrição temporal ajuda a reduzir a influência de variáveis omitidas potencialmente importantes para explicar o sucesso eleitoral de chefes de governo, como o bom desempenho econômico. ${ }^{7}$

Para avaliar as hipóteses enunciadas, o método utilizado foi o da análise comparada qualitativa (ACQ; ou QCA na abreviação em inglês). Trata-se de uma técnica desenvolvida originalmente por Ragin (1987) e popularizada rapidamente nas ciências sociais. É adequada para desenhos de pesquisa como a deste trabalho, em que o objetivo é verificar se a ocorrência de um evento ou combinação de eventos explica a ocorrência de outro evento; isto é, desenhos de pesquisa em que todas as variáveis são binárias. É também adequada para um banco de dados com número restrito de observações. A análise requer conhecimento relativamente mais profundo dos casos e se orienta mais fortemente por suas diferenças categóricas, tornando profícua a utilização de métodos qualitativos. Modelos de regressão tenderiam a produzir erros padrões muito grandes e resultados imprecisos. Nestes casos, a probabilidade de erros tipo II poderia ser alta demais, levando-nos a aceitar a hipótese nula quando ela é falsa. Por isto, optei por seguir uma abordagem metodológica qualitativa. A ACQ se baseia na álgebra booleana para verificar se diferentes combinações de eventos produzem o resultado de interesse. Com base nesta técnica é possível identificar causas suficientes, quando observamos que sempre que um evento acontece (digamos, o controle sobre o Legislativo), o resultado de interesse também ocorre (digamos, a sobrevivência do Executivo). Se aquele evento não ocorresse, seria ainda possível que o efeito fosse observado. Também é possível identificar causas necessárias, quando um efeito só é observado na ocorrência de um dado evento. Neste caso, não há efeito sem o evento.

O primeiro passo é operacionalizar as variáveis dependente e independentes, todas binárias. A variável dependente, denominada "Sobrevivência", indica que o presidente ou o candidato apoiado por ele venceu a eleição. Presidentes sobrevivem vencendo por um voto ou com $90 \%$ dos votos, e é só o resultado substantivo, isto é, a vitória eleitoral, que importa. Se possuem tendências autoritárias e querem sobreviver a todo custo, poderiam fraudar resultados para alcançar 50\% mais um dos votos válidos ou utilizar as forças de segurança para esmagar a oposição e alcançar 90\%. Isto é, a margem de vitória não nos permite dizer muita coisa sobre o grau de competitividade ou lisura das eleições. Para os propósitos deste trabalho, importa apenas saber se o presidente foi capaz de sobreviver no momento onde o seu risco de queda é maior. Há três casos em que o presidente em exercício assumiu interinamente após o impeachment ou renúncia do eleito no último pleito: Honduras em 2009, Paraguai em 2013 e Guatemala em 2015. Todos eles foram codificados como " 0 ”, pois o presidente eleito na eleição correspondente não se alinhava nem ao presidente deposto, nem ao em exercício. Isto é, o vitorioso na eleição anterior não sobreviveu.

São três as variáveis independentes que, de acordo com as hipóteses enunciadas acima, explicam a sobrevivência de um líder ou grupo político no poder: controle sobre o Legislativo, controle sobre a sociedade civil e ideologia radical de esquerda. Todas são também binárias. Para definir se o grupo político no poder tinha total controle sobre o poder Legislativo, primeiro eu verifiquei se o seu partido controlava sozinho a maioria das cadeiras da Câmara baixa ou única. Como disse na seção anterior, este deveria ser um fenômeno raro, dado que todos os países alocam pelo menos parte das cadeiras com base na fórmula de representação proporcional. A variável se baseia nos resultados das últimas eleições legislativas antes da eleição presidencial e, portanto, ignora possíveis trocas de partidos durante o mandato parlamentar. ${ }^{8}$ Esses resultados são de conhecimento público, amplamente divulgados e podem ser facilmente obtidos 
dois meses e meio antes das eleições presidenciais, foram consideradas as eleições legislativas realizadas quatro anos antes.

9 A Argentina e o México realizam eleições legislativas no meio do mandato presidencial e El Salvador, República Dominicana (até 2016) e Venezuela não realizam eleições concomitantes para os dois poderes.

${ }^{10} \mathrm{O}$ banco de dados do V-DEM pode ser obtido gratuitamente no site do projeto, conforme referências. A versão mais recente em 07/2018 (versão 8) foi a utilizada neste trabalho. $\mathrm{O}$ código da variável em que me baseei é

"e_v2xlg_legcon_5C".

11 Informações sobre a metodologia e as fontes de dados utilizadas pelo Banco Mundial para construir este indicador podem ser encontradas no site do próprio banco, conforme referências.

12 Os bancos de dados do Barômetro das Américas podem ser acessados gratuitamente no site do Latin American Public Opinion Project - LAPOP, conforme referências. A questão que utilizei para operacionalizar este indicador pede para o em relatórios oficiais disponíveis na internet. Assim, foi possível observar se o atual presidente governou com maioria unipartidária durante todo o seu mandato, ou pelo menos nos últimos anos antes da eleição presidencial. ${ }^{9}$ Em segundo lugar, verifiquei se o Legislativo "questiona, investiga e fiscaliza" o Executivo rotineiramente. Esta informação foi extraída da última versão do banco de dados do projeto Variedades de Democracia (V-DEM) e é baseada na opinião de especialistas recrutados pela equipe do projeto. Utilizei a versão ordinal de cinco categorias desta variável e codifiquei como 1 os casos classificados nas três categorias inferiores, isto é, de menor grau de fiscalização do Executivo por parte do Legislativo. ${ }^{10}$ Finalmente, só receberam o valor "1" na variável independente "Controle sobre o Legislativo" os casos que satisfizeram ambas as condições: maioria unipartidária no Legislativo e baixo grau de fiscalização do Executivo pelo Legislativo. Todos os demais foram codificados como “0”.

A segunda variável independente, denominada "Controle sobre a Sociedade Civil", mede a capacidade do Executivo de orientar a produção de políticas públicas para a consolidação de uma base estável de apoio na sociedade civil. Para que isto seja possível, duas condições são necessárias. Primeiro, a administração pública do Estado deve ser politizada e capaz de estampar símbolos partidários nos benefícios e serviços sociais implementados pelo governo, de modo que o cidadão perceba esses benefícios e serviços como dependentes da manutenção do atual partido no poder. Dito de outro modo, a implementação de políticas sociais pelo Estado não deve se orientar pelos princípios da burocracia weberiana, mas seguir uma orientação político-partidária. Para medir o grau de politização da administração pública estatal, baseei-me no indicador de "Efetividade Governamental", compilado anualmente pelo Banco Mundial. Trata-se de um índice construído a partir de múltiplas fontes de dados, principalmente surveys de analistas, que mede "a qualidade dos serviços públicos, a qualidade do serviço civil e o seu grau de independência de pressões políticas, a qualidade da formulação e implementação de políticas e a credibilidade do compromisso do governo com essas políticas". ${ }^{11}$ Este indicador é padronizado para variar entre $-2,5$ e 2,5, sendo que valores negativos indicam menor grau de efetividade governamental. Considerei administrações públicas mais susceptíveis à politização pelo partido no controle do Executivo todas as que receberam valores negativos durante a maioria dos anos do mandato do presidente.

A segunda condição necessária para que o Estado obtenha controle político sobre a sociedade civil é o incentivo à participação direta do cidadão comum na produção de políticas públicas em instâncias reguladas pelo Estado. Embora em países com administração pública impessoal e burocratizada esses mecanismos possam canalizar interesses plurais da sociedade civil e se tornar espaços de efetiva deliberação pública no sentido habermasiano, em países com administrações públicas politizadas, as instituições participativas tendem antes à doutrinação política. A evidência mais forte disto é o fato de o incentivo governamental à participação ser muito maior neste segundo caso do que no primeiro. Portanto, para indicar a utilização de instituições participativas como mecanismo de doutrinação política e controle social, observei a proporção da população nacional que participa de conselhos comunitários. Esta informação foi extraída dos surveys do Barômetro das Américas realizados no ano da eleição ou imediatamente anterior. ${ }^{12}$ Foram consideradas instituições participativas cooptadas pelo governo os casos em que $25 \%$ ou mais da população declara participar com alguma frequência de conselhos comunitários. Um número tão elevado quanto este pode denotar uma pró-atividade atípica do Estado para incentivar a participação direta da sociedade civil em fóruns deliberativos, a fim de controlá-la politicamente. A variável "Controle sobre a Sociedade Civil" é binária e indica a existência simultânea destas duas condições: uma administração pública politizada e uma ampla participação da sociedade civil em 
entrevistado indicar a frequência com que participa de "reunião de uma associação de bairro ou junta de melhorias para a comunidade" e é codificada como "CP8" nos surveys.

\footnotetext{
13 Trecho original em inglês: "Parties that employ Marxist ideology or rhetoric and stress the priority of distribution over accumulation and/or the exploitation of the working class by capitalists and imperialists and advocate a strong role for the state to correct social and economic injustices."
}

\section{Resultados}

conselhos comunitários. Quando uma dessas condições ou ambas estiveram ausentes, a observação recebeu o valor " 0 ".

Com base no atual estado da literatura, é difícil associar teoricamente a ideologia do partido governista à sua capacidade de controle efetivo do Legislativo e da sociedade civil. Há, no entanto, razões para acreditarmos que a agenda da esquerda radical pode, ela mesma, aumentar a popularidade de presidentes em países pobres e tornar suas administrações mais longevas e eleitoralmente bem-sucedidas, como argumentei na seção anterior. Para identificar presidentes alinhados à esquerda radical, baseei-me em informações do banco de dados de Baker e Greene (2011), que os próprios autores atualizaram até 2016 e disponibilizaram em seus sites pessoais. Os autores codificaram a ideologia dos presidentes através da escala de zero a vinte desenvolvida originalmente por Wiesehomeier e Benoit (2009), na qual valores baixos indicam "esquerda" e valores altos indicam "direita". Quanto mais próximas de zero ou vinte, mais extremistas são as posições do presidente. Classifiquei como radicais de esquerda todos aqueles posicionados no quarto inferior da escala (valores menores que cinco). Estes casos são os mesmos classificados como "esquerda" por Huber e Stephens (2012), com base nas categorias propostas por Coppedge (1997), para quem são de esquerda os "partidos que usam ideologia ou retórica marxista e enfatizam a prioridade da distribuição sobre a acumulação e/ou a exploração da classe trabalhadora pelos capitalistas e imperialistas e advogam um forte papel do Estado para corrigir injustiças sociais e econômicas" (Coppedge, 1997, p. 8, tradução minha). ${ }^{13}$ A Tabela 1 apresenta os valores de todas as variáveis para todos os casos analisados neste trabalho.

Note que quase metade dos casos se referem à combinação de variáveis independentes (0-0-0), demonstrando que o padrão atual no continente é o de presidentes não alinhados à esquerda radical que não controlam o Legislativo ou a sociedade civil. Por outro lado, a esquerda radical tem sido muito mais bem-sucedida em obter ambos os tipos de controle. Felizmente há casos correspondentes a outras combinações de valores, tornando possível a aplicação da ACQ.

Com base nos dados coletados, é possível construir uma tabela-verdade para avaliar a relação entre as diferentes combinações de valores das variáveis independentes e o resultado esperado da variável dependente. Ela é útil para identificar combinações distintas que levam a resultados similares e, assim, eliminar variações consideradas irrelevantes. A Tabela 2 apresenta a tabelaverdade construída a partir dos dados da Tabela 1. Salta aos olhos, em primeiro lugar que quatro combinações de valores das variáveis independentes sempre se associam à vitória eleitoral do chefe de governo. Estas combinações estão destacadas em cinza na Tabela 2.

Algumas ressalvas são necessárias antes de prosseguirmos à interpretação. Em primeiro lugar, note que das quatro combinações que se associam a 100\% de casos de sobrevivência do partido no poder Executivo, uma delas se baseia em apenas um caso (1-0-0) e outra em apenas dois (0-0-1). O baixo número de casos para certas combinações não tende a ser considerado um problema capaz de desqualificar conclusões alcançadas através da metodologia ACQ, pois trata-se de um método apropriado justamente para amostras pequenas. Em segundo lugar, observe que para duas combinações de valores (1-0-1 e 0-1-1), não há nenhum caso na amostra. Para estas combinações hipotéticas não é possível arriscar qualquer previsão com relação ao efeito esperado. Em terceiro lugar, para as duas combinações restantes (0-1-0 e 0-0-0), os resultados são contraditórios e também não nos permite determinar se promovem ou não a 
${ }^{14}$ Os únicos três casos de não sobrevivência política em virtude de impeachment ou renúncia (Guatemala 2015, Honduras 2009 e Paraguai 2013) se referem a estas combinações. Ainda que os respectivos presidentes tivessem cumprido seus mandatos e sobrevivido às eleições seguintes, não poderiam alterar a conclusão de que as combinações 0-1-0 e 0-0-0 geram incerteza eleitoral, pois haveriam outros casos de derrota eleitoral associados a elas. sobrevivência do governo. Podemos afirmar com segurança, entretanto, que as variáveis independentes combinadas assim não garantem esta sobrevivência, o que é, por si só, um achado de grande importância substantiva ${ }^{14}$ Incerteza,

Tabela 1 - Banco de dados de sobrevivência eleitoral

\begin{tabular}{|c|c|c|c|c|}
\hline Eleição & $\begin{array}{c}\text { Controle } \\
\text { Legislativo }\end{array}$ & $\begin{array}{c}\text { Controle } \\
\text { Sociedade Civil }\end{array}$ & $\begin{array}{c}\text { Esquerda } \\
\text { Radical }\end{array}$ & Sobrevivência \\
\hline Bolívia 2009 & 1 & 1 & 1 & 1 \\
\hline Bolívia 2014 & 1 & 1 & 1 & 1 \\
\hline Equador 2009 & 1 & 1 & 1 & 1 \\
\hline Equador 2017 & 1 & 1 & 1 & 1 \\
\hline Venezuela 2012 & 1 & 1 & 1 & 1 \\
\hline Venezuela 2013 & 1 & 1 & 1 & 1 \\
\hline Nicarágua 2016 & 1 & 1 & 0 & 1 \\
\hline Rep Dominicana 2012 & 1 & 1 & 0 & 1 \\
\hline Rep Dominicana 2016 & 1 & 1 & 0 & 1 \\
\hline Honduras 2013 & 1 & 0 & 0 & 1 \\
\hline Guatemala 2011 & 0 & 1 & 0 & 0 \\
\hline Guatemala 2015 & 0 & 1 & 0 & 0 \\
\hline Honduras 2017 & 0 & 1 & 0 & 1 \\
\hline Nicarágua 2011 & 0 & 1 & 0 & 1 \\
\hline Paraguai 2013 & 0 & 1 & 0 & 0 \\
\hline Peru 2011 & 0 & 1 & 0 & 0 \\
\hline Peru 2016 & 0 & 1 & 0 & 0 \\
\hline Equador 2013 & 0 & 0 & 1 & 1 \\
\hline El Salvador 2014 & 0 & 0 & 1 & 1 \\
\hline Argentina 2011 & 0 & 0 & 0 & 1 \\
\hline Argentina 2015 & 0 & 0 & 0 & 0 \\
\hline Brasil 2010 & 0 & 0 & 0 & 1 \\
\hline Brasil 2014 & 0 & 0 & 0 & 1 \\
\hline Chile 2009 & 0 & 0 & 0 & 0 \\
\hline Chile 2013 & 0 & 0 & 0 & 0 \\
\hline Chile 2017 & 0 & 0 & 0 & 0 \\
\hline Colômbia 2010 & 0 & 0 & 0 & 1 \\
\hline Colômbia 2014 & 0 & 0 & 0 & 1 \\
\hline Costa Rica 2010 & 0 & 0 & 0 & 1 \\
\hline Costa Rica 2014 & 0 & 0 & 0 & 0 \\
\hline El Salvador 2009 & 0 & 0 & 0 & 0 \\
\hline Honduras 2009 & 0 & 0 & 0 & 0 \\
\hline México 2012 & 0 & 0 & 0 & 0 \\
\hline Panamá 2009 & 0 & 0 & 0 & 0 \\
\hline Panamá 2014 & 0 & 0 & 0 & 0 \\
\hline Uruguai 2009 & 0 & 0 & 0 & 1 \\
\hline Uruguai2014 & 0 & 0 & 0 & 1 \\
\hline
\end{tabular}

Fonte: $\mathrm{O}$ autor, com base nas fontes identificadas no texto. 
Tabela 2 - Tabela-verdade com dados da Tabela 1

\begin{tabular}{cccccc}
\hline $\begin{array}{c}\text { Controle } \\
\text { Legislativo }\end{array}$ & $\begin{array}{c}\text { Controle } \\
\text { Sociedade Civil }\end{array}$ & $\begin{array}{c}\text { Esquerda } \\
\text { Radical }\end{array}$ & $\mathbf{N}$ & $\begin{array}{c}\text { N - } \\
\text { Sobrevivência }\end{array}$ & $\begin{array}{c}\text { Cód. } \\
\text { Resultado }\end{array}$ \\
\hline 1 & 1 & 1 & 6 & $6(100 \%)$ & 1 \\
1 & 1 & 0 & 3 & $3(100 \%)$ & 1 \\
1 & 0 & 1 & 0 & 0 & $?$ \\
1 & 0 & 0 & 1 & $1(100 \%)$ & 1 \\
0 & 1 & 1 & 0 & 0 & $?$ \\
0 & 1 & 0 & 7 & $2(29 \%)$ & $?$ \\
0 & 0 & 1 & 2 & $2(100 \%)$ & 1 \\
0 & 0 & 0 & 18 & $8(44 \%)$ & $?$ \\
\hline
\end{tabular}

Fonte: $\mathrm{O}$ autor, com base em informações da Tabela 1.

alternância de poder e riscos para a sobrevivência do governo após disputas eleitorais é, via de regra, considerada uma virtude democrática. Finalmente, note também que nenhuma combinação de valores promove necessariamente a derrota eleitoral do governo, isto é, a tabela não apresenta combinações de valores que levam sempre a este resultado.

A expressão booleana que explica a sobrevivência de líderes ou de seus partidos no poder Executivo é:

\section{SOBREVIVÊNCIA =}

CONT.LEG $*$ CONT.SOC.CIVIL $*$ ESQ.RADICAL + CONT.LEG $*$ CONT.SOC.CIVIL * esq.radical + CONT.LEG $*$ cont.soc.civil $*$ esq.racical + cont.leg * cont.soc.civil * ESQ.RADICAL

Nesta expressão, letras maiúsculas denotam a presença da condição indicada pela variável e letras minúsculas denotam ausência. O sinal de multiplicação indica a presença ou ausência simultânea das condições. Por exemplo, o presidente se perpetua no poder quando controla o Legislativo, a sociedade civil e é radical de esquerda (CONT.LEG * CONT.SOC.CIVIL * ESQ.RADICAL), assim como em outras três circunstâncias. O sinal de adição é utilizado para enumerar as outras combinações possíveis de valores que levam ao mesmo resultado. Assim, o presidente também sobrevive quando controla o Legislativo e a sociedade civil, mesmo sem ser radical de esquerda (CONT.LEG * CONT.SOC.CIVIL * esq.radical). Após redução booleana, a expressão se

15 A técnica de redução booleana consiste na identificação e eliminação de variáveis irrelevantes para explicar o resultado de interesse. Por exemplo, as duas primeiras combinações da equação (1) mostram que quando há controle do legislativo e da sociedade civil, o presidente sobrevive eleitoralmente independentemente de ser radical de esquerda. Assim, na presença daquelas duas condições, a ideologia do presidente não importa, como denota o termo "CONT.LEG * CONT.SOC.CIVIL" da equação 2. A mesma lógica foi torna: ${ }^{15}$

\section{SOBREVIVÊNCIA =}

CONT.LEG * CONT.SOC.CIVIL + CONT.LEG * esq.radical + cont.leg * cont.soc.civil * ESQ.RADICAL

A expressão (2) indica que o líder e seu partido sobrevivem no governo quando: 1- ele controla o Legislativo e a sociedade civil (nesses casos, ser ou não radical de esquerda é irrelevante); 2- ele controla o Legislativo e não é radical de esquerda (nesses casos, controlar ou não a sociedade civil é irrelevante) ou 3- ele não controla nem o Legislativo nem a sociedade civil, mas é radical de esquerda. Isto quer dizer também que os dados não me permitem afirmar que qualquer das condições indicadas pelas variáveis independentes é, individualmente, condição suficiente para a sobrevivência do chefe do Executivo. Na equação (2), isto é evidenciado pela ausência de condições capazes de determinar o resultado de interesse sem se combinar com outra. É preciso ressaltar, no entanto, que isto pode se dever antes à limitação dos dados e à necessidade de 
aplicada para se chegar aos outros dois termos. Para uma explicação didática sobre o método ACQ e a técnica de redução booleana, consultar Ragin (1987)

\section{Conclusões}

extrairmos conclusões conservadoras, do que ao fato de realmente não haver uma causa suficiente entre as variáveis utilizadas. Todos os presidentes da amostra que controlaram o Legislativo venceram a eleição ou elegeram seu sucessor, assim como todos os presidentes classificados como radicais de esquerda. Não sabemos o que ocorreria se um presidente radical de esquerda controlasse apenas o Legislativo e não a sociedade civil, ou controlasse apenas a sociedade civil e não o Legislativo, porque no período analisado só há casos de radicais de esquerda que controlaram ambos ou nenhum deles.

Tampouco somos capazes de identificar causas necessárias para a vitória eleitoral dos chefes do Executivo dentre as variáveis que entraram na análise. Na equação (2), isto é evidenciado pela ausência de uma condição presente em todas as combinações possíveis que levam ao resultado de interesse. Aparentemente, a esquerda radical consegue sobreviver mesmo sem controlar o Executivo e a sociedade civil, já que não foram observados casos de derrotas entre seus líderes no período estudado. Por outro lado, não é necessário que o líder seja radical de esquerda para sobreviver. A expressão (2) indica que isto seria possível com governos de qualquer ideologia, desde que controlassem o Legislativo e a sociedade civil. Tudo o que temos até o momento é uma expressão reduzida que identifica fatores associados à sobrevivência de certos grupos políticos no poder. Esta expressão traz insights importantes para a compreensão da conjuntura latino-americana após crise financeira global de 2008.

Este artigo foi motivado pela ocorrência de um cenário político intrigante na América Latina. A instabilidade econômica que se alastrou pelo continente após a crise financeira global de 2008 deveria ter colocado em xeque a sobrevivência dos governos latino-americanos. Isto de fato ocorreu. Presidentes de esquerda caíram em função de impeachment ou derrotas eleitorais na Argentina, Brasil, Chile, Paraguai e Peru. Em outros países, também ocorreram derrotas políticas que não levaram à queda do presidente. A oposição conquistou a maioria das cadeiras legislativas na Venezuela em 2015 e referendos para instituir a reeleição sem limites foram rejeitados na Bolívia em 2016 e no Equador em 2018. Na Nicarágua, Ortega foi obrigado a cancelar medidas importantes, como a proposta de elevação de contribuições previdenciárias, em virtude de protestos violentos. Apesar disto, os governantes destes países resistem no cargo (em fins de 2018). São acompanhados por governos já relativamente longevos em Honduras, República Dominicana e Uruguai (em fins de 2018). Como explicar a maior resiliência de algumas forças políticas em circunstâncias que têm se mostrado tão ou mais graves do que aquelas geralmente aludidas para explicar a queda de outros?

Este artigo se propôs a investigar a influência de três mecanismos: o controle do governo sobre o Legislativo, o controle sobre a sociedade civil e uma possível maior popularidade da agenda da esquerda radical. Quatro das oito combinações entre essas variáveis promoveram a sobrevivência política de administrações presidenciais em $100 \%$ das observações. Redução booleana permitiu identificar três situações em que este evento ocorre. A primeira é o controle sobre o Legislativo e a sociedade civil por um presidente que se alinha a qualquer que seja a corrente ideológica. Este achado está de acordo com os pressupostos teóricos que motivaram minha análise e ajuda a explicar, por exemplo, a resiliência do PLD na República Dominicana e de Daniel Ortega, um esquerdista considerado mais próximo ao centro pela literatura, na Nicarágua. A segunda situação é a de um governo que controla o Legislativo e não é radical de esquerda, independentemente de controlar ou não a sociedade civil. Este resultado ajuda a compreender a resiliência do $\mathrm{PNH}$, um partido conser- 
vador, em Honduras. Finalmente, a terceira situação diz respeito a um governa radical de esquerda que não controla nem o Legislativo, nem a sociedade civil. Esta situação foi verificada quando Rafael Corrêa disputou a segunda reeleição em 2013 e quando a Frente Farabundo Martí para la Liberación Nacional (FMLN) elegeu o sucessor de Maurício Funes em El Salvador em 2014.

Os mecanismos de controle estudados aqui são muito difíceis de se obter em países democráticos, quando a sociedade pode se organizar de forma autônoma e a alocação de cadeiras no Legislativo se dá pela fórmula da representação proporcional. Os atuais presidentes da Bolívia, Equador e Venezuela (em fins de 2018), todos radicais de esquerda, só obtiveram estes controles após processos constituintes que refundaram as instituições nacionais. Estas reformas ocorreram numa conjuntura de alta instabilidade política e forte descontentamento popular com os partidos e elites tradicionais. Em Honduras, Nicarágua e República Dominicana, onde novas Constituições não foram adotadas recentemente, as instituições herdadas pelos atuais governos favoreceram essas formas de controle. Para concretizá-las, bastou apenas que um político inábil sabotasse o próprio partido no primeiro caso e que um político hábil tirasse vantagem das possibilidades institucionais de seu país nos outros dois casos. O que estes seis casos demonstram em conjunto é a impressionante capacidade que o controle sobre o Legislativo e a sociedade civil possui para dar sobrevida a governantes, mesmo que em condições econômicas desfavoráveis.

Diego Sanches Corrêa (diego.correa@ufabc.edu.br) é doutor em Ciência Política pela Universidade de Illinois em Urbana-Champaign, EUA, e professor de Políticas Públicas da UFABC.

\section{Referências}

Anastasia, F., Melo, C.R. \& Santos, F. 2004. Governabilidade e Representação Política na América do Sul. Rio de Janeiro, São Paulo: Fundação Adenauer / Unesp.

Baker, A. \& Greene, K.F. 2011. The Latin American Left's Mandate: Free-Market Policies and Issue Voting in New Democracies. World Politics, 63(1), pp. 43-77. DOI: 10.1017/S0043887110000286

Castañeda, J.G. 2006. Latin America's Left Turn. Foreign Affairs, 85(3), pp. 28-43. DOI: 10.2307/20031965.

Coppedge, M. 1997. A Classification of Latin American Political Parties. Kellogg's Institute for International Studies, Working Paper \#244. [online] Disponível em: https://kellogg.nd.edu/documents/1539. (Acesso em: 13 mai. 2020).

Corrêa, D.S. 2015. Conditional Cash Transfer Programs, the Economy, and Presidential Elections in Latin America. Latin American Research Review, 50(2), pp. 63-85.

Flores-Macías, G.A. 2010. Statist vs. Pro-Market: Explaining Leftist Governments' Economic Policies in Latin America. Comparative Politics, 42(4), pp. 413-433.

Handlin, S. 2013. Social Protection and the Politicization of Class Cleavages During Latin America's Left Turn. Comparative Political Studies, 46(12), pp. 1582-1609. DOI: 10.1177/0010414012463907

Levitsky, S. \& Roberts, K. 2011. 'Latin America's “Left Turn”: A Framework for Analysis'. In: Levitsky, S. \& Roberts, K. (eds.) The Resurgence of the Latin American Left. Baltimore, Maryland: Johns Hopkins University Press, pp. 1-28.

Linz, J. 1991. Presidencialismo ou Parlamentarismo: Faz alguma diferença? In: A Opção Parlamentarista. Sumaré: Editora IDESP, pp. 61-120.

Madrid, R.L. 2010. The Origins of the Two Lefts in Latin America. Political Science Quarterly, 125(4), pp. 587-609. DOI: 10.1002/j.1538-165X.2010.tb00686.x

Mainwaring, S. 2018. Party System Institutionalization in Contemporary Latin America. In: Mainwaring, S. (ed.) Party Systems in Latin Americas: Institutionalization, Decay, and Collapse. Cambridge, UK: Cambridge University Press, pp. 34-70.

O’Donnell, G. 1994. Delegative Democracy. Journal of Democracy, 5(1), pp. 55-69. DOI: 10.1353/jod.1994.0010

Ragin, C.C. 1987. The Comparative Method: Moving Beyond Qualitative and Quantitative Strategies. Oakland, CA: University of California Press.

Remmer, K.L. 1991. The Political Impact of Economic Crisis in Latin America in the 1980s. The American Political Science Review, 85(3), pp. 777-800. DOI: 10.2307/1963850.

Samuels, D. 2004. Presidentialism and Accountability for the Economy in Comparative Perspective. American Political Science Review, 98(3), pp. 425-436. DOI: 10.1017/S000305540400125X.

Silva, F.P. 2015. Democracias Errantes: Reflexões sobre experiências participativas na América Latina. Rio de Janeiro, RJ: Ponteio. 
Silva, F.P. 2016. Padrões de Participação em Governos de Esquerda na América Latina: Brasil e Venezuela em Perspectiva Comparada. Dados - Revista de Ciências Sociais, 59(3), pp. 651-681. DOI: 10.1590/00115258201688.

Weyland, K. 2009. The Rise of Latin America's Two Lefts: Insights from Rentier State Theory. Comparative Politics, 41(2), pp. 145-164.

Wiesehomeier, N. \& Benoit, K. (2009) Presidents, Parties, and Policy Competition. The Journal of Politics, 71(4), pp. 1435-1447. DOI: 10.1017/s0022381609990193.

\section{Outras fontes}

Baker, A. Latin American Election Results with Party Ideology Scores 2.0. Disponível em: https://www.colorado.edu/faculty/baker/data (Acesso em 15 mai. 2020).

Banco Mundial, Worldwide $\quad$ Governance Disponível em: http://info.worldbank.org/governance/wgi/index.aspx\#home (Acesso em 15 mai. 2020).

Comissão Econômica para a América Latina e Caribe, CEPALSTAT. Disponível em: https://estadisticas.cepal.org/cepalstat/portada.html (Acesso em 15 mai. 2020).

Fundo Monetário Internacional. World Economic Outlook Database. Disponível em: https://www.imf.org/en/Publications/SPROLLs/world-economic-outlook-databases\#sort=\%40imfdate\%20descending (Acesso em: 15 mai. 2020).

Huber, E. \& Stephens, J.D. 2012. Latin American and the Caribbean Political Dataset, 1945-2012. University of North Carolina. Disponível em: http://huberandstephens.web.unc.edu/common-works/data/. (Acesso em: 14 mai. 2020).

Latin American Public Opinion Project (LAPOP), Vanderbilt University. Disponível em: https://www.vanderbilt.edu/lapop/ (Acesso em 15 ma. 2020).

Varieties of Democracy. Disponível em: https://www.v-dem.net/en/ (Acesso em: 15 mai. 2020).

\section{Glossário de siglas}

ABCP - Associação Brasileira de Ciência Política

ACQ - Análise Comparada Qualitativa

CEPALSTAT - Base de dados e publicações estatísticas da CEPAL

CONT.LEG - Controle Legislativo

CONT.SOC.CIVIL - Controle Sociedade Civil

ESQ.RADICAL - Esquerda Radical

FPV - Frente para la Victoria

LAPOP - Latin American Public Opinion Project

PAC - Partido Acción Ciudadana

PAN - Partido Acción Nacional

PJ - Partido Justicialista

PLD - Partido da Libertação Dominicana

PNH - Partido Nacional de Honduras

PRI - Partido Revolucionario Institucional

PSUV - Partido Socialista Unida da Venezuela

PT - Partido dos Trabalhadores

QCA - Qualitative Comparative Analysis

UCR - Unión Cívica Radical

V-DEM - Variedades de Democracia 
Electoral resilience of Latin American presidents after the crisis of 2008 and the ebb of the pink tide

ABSTRACT Introduction: The goal of this article is to explain Latin American presidents' capacity to survive electorally in conditions of political and economic instability. Materials and Methods: I tested three hypotheses. Presidents have higher capacity of surviving when: 1 - they control the Legislative Power; 2 - they control the civil society, and 3-they are aligned to the radical left. All the variables used in this article are binary and the methodology applied was the Qualitative Comparative Analysis (QCA). Results: On the one hand, my analysis shows that none of the independent variables are, by itself, either a sufficient or a necessary condition for the electoral survival of Latin American presidents. On the other hand, they show that controlling the Legislative Power and the civil society promotes the survival of presidents identified with any ideology, and that radical leftist presidents survive even when those controls are absent. Discussion: These results help to explain a ringing fact of the Latin American political conjuncture in the post-global crisis of 2008: the strong resilience of some presidents in highly adverse conditions. Whereas alternation in power occurred in several countries ruled by the same party for more than a decade, in others, mechanisms of electoral accountability seem to have failed to promote changes in government

KEYWORDS: presidential elections; Latin America; radical left; electoral survival; QCA.

This is an Open Access article distributed under the terms of the Creative Commons Attribution Non-Commercial License which permits unrestricted non-commercial use, distribution, and reproduction in any medium provided the original work is properly cited.

A produção desse manuscrito foi viabilizada através do patrocínio fornecido pelo Centro Universitário Internacional Uninter à Revista de Sociologia e Política. 